\title{
Traumatic Brain Injury in Pregnancy
}

\section{Traumatismo cranioencefálico na gravidez}

\author{
Letícia Adrielle dos Santos ${ }^{10}$ Carlos Umberto Pereira ${ }^{2}{ }^{\circ}$ Maycon Cristian Gomes de Paula ${ }^{30}$ \\ Gabriela Ferreira Kalkmann ${ }^{4}$ (i) Nicollas Nunes Rabelo ${ }^{5(1)}$
}

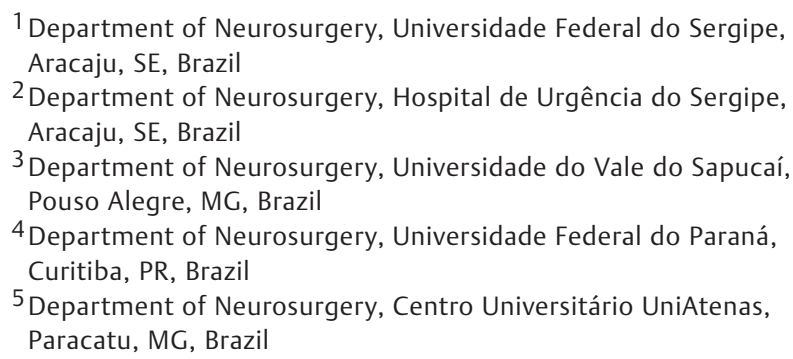

Address for correspondence Nícollas Nunes Rabelo, MD, Av. Antônio Diederichsen, $n^{\circ}$ 190, Ap. 193, Jardim América, 14.020-250, Ribeirão Preto, SP, Brazil (e-mail: nicollasrabelo@hotmail.com).

Arq Bras Neurocir

\section{Abstract \\ Keywords \\ - traumatic brain injury \\ - pregnancy \\ - management \\ - developmental disabilities \\ - persistent vegetative state}

\section{Resumo}

Objective The present paper aims to provide a review on the main complications involving traumatic brain injury (TBI) during pregnancy and on the vegetative state after TBI.

Methods A systematic review was performed in concordance with the Preferred Reporting Items for Systematic Reviews and Meta-Analyses (PRISMA) criteria checklist. Results Seven studies were included, of which four were case reports, one was a follow-up, one was a comparative study, and one was a literature review.

Discussion Presence of neurological deficits such as hemiparesis, neonatal seizures, cerebral palsy, hemorrhage or hydrocephalus was observed in children of mothers who suffered trauma during pregnancy. The prolongation of a pregnancy in these victims, even in brain death, is within the reach of current medicine. Ethical issues must be considered when deciding to prolong a pregnancy of a woman in brain death.

Conclusion For the evaluation of pregnant women with TBI, there is a protocol that can be followed in the emergency care service. The cases reported in the literature suggest that there is no clear limit to restrict support to a pregnant patient in a vegetative state. Further studies should be done to elucidate this matter.

Objetivo O presente artigo buscou revisar as principais complicações envolvendo lesão cerebral traumática durante a gravidez e sobre estado vegetativo após esse trauma. Métodos Uma revisão sistemática foi realizada de acordo com o checklist dos critérios Principais itens para relatar Revisões sistemáticas e Metanálises (PRISMA, na sigla em inglês). received

August 1, 2020

accepted

March 9, 2021
DOI https://doi.org/ 10.1055/s-0041-1733862. ISSN 0103-5355.

\footnotetext{
C 2022. Sociedade Brasileira de Neurocirurgia. All rights reserved. This is an open access article published by Thieme under the terms of the Creative Commons Attribution-NonDerivative-NonCommercial-License, permitting copying and reproduction so long as the original work is given appropriate credit. Contents may not be used for commercial purposes, or adapted, remixed, transformed or built upon. (https://creativecommons.org/ licenses/by-nc-nd/4.0/) Thieme Revinter Publicações Ltda., Rua do Matoso 170, Rio de Janeiro, RJ, CEP 20270-135, Brazil
} 


\author{
Palavras-chave \\ - traumatismo \\ cranioencefálico \\ - gravidez \\ - gestão \\ - deficiências de \\ desenvolvimento \\ - estado vegetativo \\ persistente
}

Resultados Sete estudos foram incluídos, dos quais quatro eram relatos de caso, um era um acompanhamento, um era um estudo comparativo, e um era uma revisão de literatura. Discussão Presença de déficit neurológico como hemiparesias, convulsões neonatais, paralisia cerebral, hemorragia e hidrocefalia foram observadas em crianças cuja mãe sofreu trauma durante a gravidez. O prolongamento da gravidez nessas vítimas, mesmo nos casos de morte cerebral, está ao alcance da medicina atual. Dilemas éticos devem ser considerados na decisão de prolongar a gravidez em mulheres com trauma cerebral. Conclusão Para avaliação de grávidas com trauma cerebral, existe um protocolo que pode ser seguido em serviços de emergência. Os casos relatados na literatura sugerem que não há um limite claro para restringir o suporte a uma paciente grávida em estado vegetativo. Mais estudos devem ser realizados para elucidar a questão.

\section{Introduction}

Exposure of women to trauma in general has increased in recent years due to their more active lifestyle. Trauma is the main cause of nonobstetric death in females between 14 and 44 years old, ${ }^{1,2}$ occurring more frequently during the $3^{\text {rd }}$ trimester of pregnancy than at any other stage in life. ${ }^{3,4}$ Severe trauma in a pregnant woman can be considered a lesion of double magnitude, ${ }^{5}$ with significant fetal mortality. ${ }^{6}$ Its occurrence varies from 6 to $7 \%$ of pregnancies, ${ }^{1,5-7}$ with hospitalization in 0.3 to $0.4 \%$ of cases. ${ }^{1,5}$

The effect of trauma on a pregnant woman depends on the gestational age, on the intensity of maternal-fetal aggression, and on the type and severity of the injury, ${ }^{5}$ and it is generally difficult to predict the possibility of fetal loss after trauma. ${ }^{1,8}$ The extent of maternal injury does not correlate with the degree of fetal injury, ${ }^{3,9}$ and it known that even small traumas can cause fetal death and premature labor. ${ }^{3}$

Nine out of 10 traumatic injuries during pregnancy are classified as minor trauma, that is, one that does not involve the abdomen, rapid decompression, deceleration or shear forces, and that the patient does not report pain, vaginal bleeding, fluid loss or decreased fetal movement; however, between 60 and $70 \%$ of the fetal losses associated with trauma are due to mild trauma. ${ }^{10,11}$ Although the risk of fetal death can be as high in an apparently trivial trauma as in a severe accident, ${ }^{12,13}$ most pregnancies continue with a relatively small intervention and are not followedup. ${ }^{14}$ The currently dominant attitude is to consider that the relative risk of having a child with cerebral palsy after exposure to trauma is not significant, ${ }^{3}$ and that the result of pregnancy is normal when no early warning symptoms are recorded. $^{15}$

Pregnant women are more susceptible to abdominal trauma than to traumatic brain injury (TBI); ${ }^{1}$ however, the importance of the latter should not be disregarded, mainly because of the possibility of causing a permanent vegetative state. $^{16,17}$ Traumatic brain injury is the factor that most contributes to nonobstetric mortality in developing countries, with $\sim 20 \%$ of cases of maternal mortality being directly correlated to TBI. ${ }^{18}$ According to Suddaby et al., out of 252 brain deaths, only $2.85 \%$, that is, 5 cases, involve pregnant women between 15 and 45 years old. ${ }^{19}$

In Brazil, it is estimated that $\sim$ between 6 and $7 \%$ of pregnancies are complicated by trauma, which shows that the incidence of trauma in pregnant women is increasing every year. Despite the cases of permanent vegetative state or of maternal brain death, the progression of pregnancy is a possibility due to the recent improvements in life support technologies, critical care management, and obstetric monitoring techniques. Despite the cases of permanent vegetative state or of maternal brain death, the progression of pregnancy is a possibility due to the recent improvements in life support technologies, critical care management, and obstetric monitoring techniques. Due to this progression, it is becoming possible to maintain the vital functions of the patient after brain death. ${ }^{20}$

The present work aims to provide a detailed review on the main complications involving TBI in pregnancy and on the vegetative state after TBI.

\section{Methods}

The present systematic review has been performed in accordance with the Preferred Reporting Items for Systematic Reviews and Meta-Analyses (PRISMA) statement (-Fig. 1).

\section{Search Strategy}

The following databases were inspected: Pubmed, LILACS, Scielo, and The Cochrane Database of Systematic Reviews. The search strategy utilized was as follows:

\section{i: "Pregnancy" \\ ii: "traumatic brain injury" \\ iii: i AND ii}

The last search was last updated in May 2020.

\section{Study Selection}

The inclusion criteria were:

1-Title with simultaneous presence of the two defined descriptors 

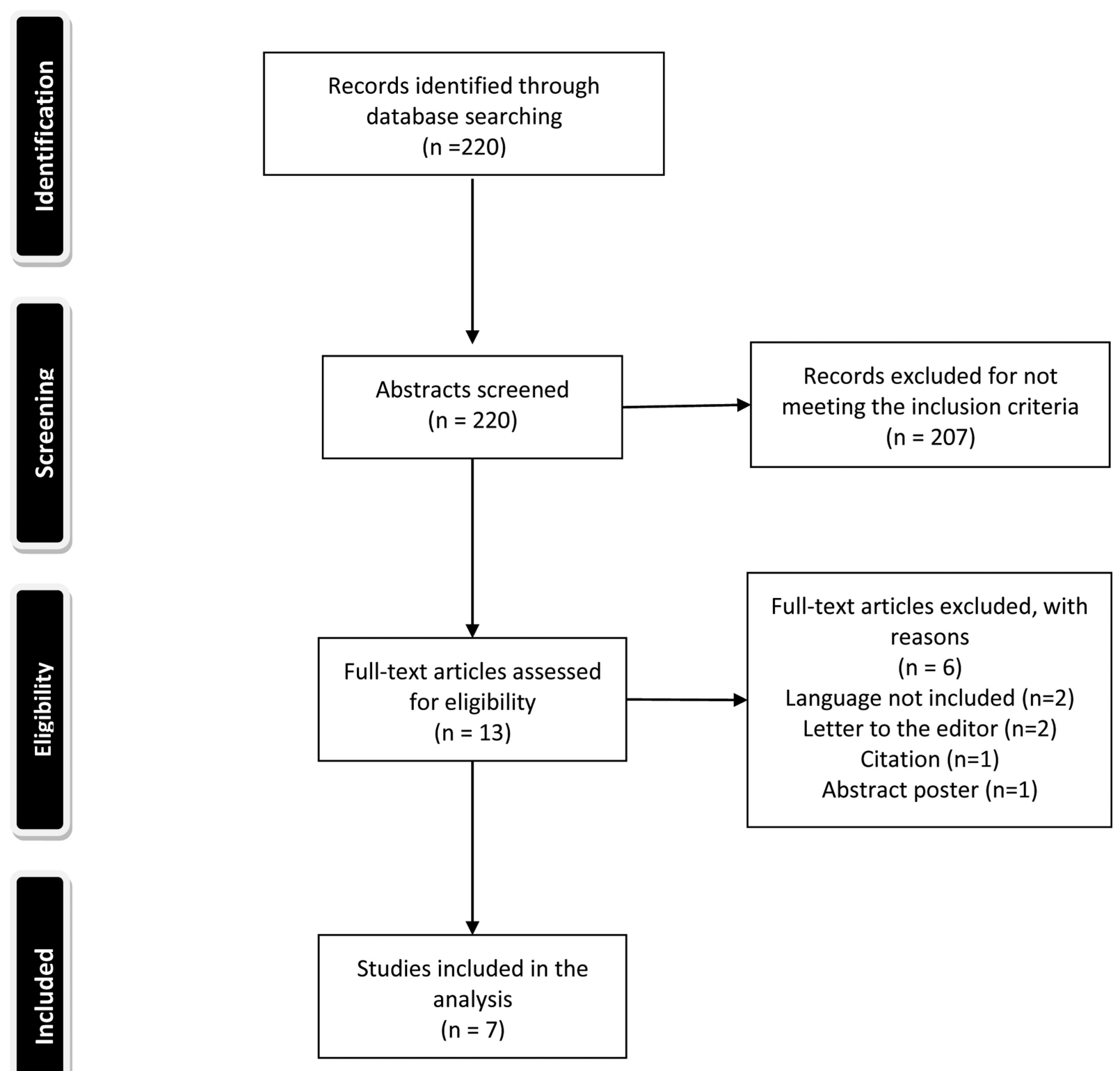

Full-text articles excluded, with reasons $(n=6)$

Language not included $(n=2)$ Letter to the editor $(n=2)$

Citation $(n=1)$ Abstract poster $(n=1)$

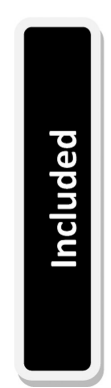

Fig. 1 PRISMA flow diagram.

2-Patient, Intervention, Control, Outcome and Study design (PICOS) criteria as below.

Patients: Pregnant women of all ages who suffered TBI. Patients who suffered nontraumatic brain injury were excluded.

Intervention/Control: Not required.

Outcomes: Recovery state based on the Glasgow Outcome Scale adapted for child, presence of injury on brain imaging, management, mortality and complications in women who suffered TBI, sequalae on fetus when the pregnant woman is in coma, and delivery route in these cases.

Study design: Full-text publications in the English language. Letter to the editor, abstract posters and citations were excluded.

\section{Results}

In our research, $4(57.14 \%)$ of the 7 articles that met the inclusion criteria were case reports, which demonstrates the lack of studies focused on this theme and on this specific study population, making the subject lacking in data goals.

The study by Berry et al. was the only one that provided data; its objective was to investigate outcomes in pregnant trauma patients with isolated moderate to severe TBI, and it was concluded that besides being younger $(24.9 \pm 7.2$ years versus $50.1 \pm 23.8$ years, $p=0.0001$ ) and having a significantly lower systolic blood pressure on admission (126.9 mm $\mathrm{Hg} 17.5$ versus $138.0 \mathrm{~mm} \mathrm{Hg} 30.5, p=0.0004$ ), there were no other significant demographic and outcome differences 
Traumatic Brain Injury in Pregnancy Santos et al.

Table 1 Systematic review

\begin{tabular}{|c|c|c|c|c|}
\hline & Authors & Year & Type & Conclusions \\
\hline \multirow[t]{7}{*}{ PubMed } & Aderet et al ${ }^{16}$ & 1984 & Case Report & $\begin{array}{l}\text { Pregnancy patients need a special maternal and fetal } \\
\text { intensive care unit, special nutrition, and fetal monitoring. }\end{array}$ \\
\hline & Leroy-Malherbe et $\mathrm{al}^{2}$ & 2006 & Follow-up & $\begin{array}{l}\text { Fetal injury comes from a wide range of mechanisms. } \\
\text { Post-traumatic evaluation of the fetus is often incomplete } \\
\text { or absent. }\end{array}$ \\
\hline & Berry et al ${ }^{21}$ & 2011 & Comparative study & $\begin{array}{l}\text { Pregnancy patients with traumatic brain injury had } \downarrow \text { Age, } \\
\downarrow \text { Systolic Blood Pressure and } \uparrow \text { mortality than their } \\
\text { nonpregnant counterparts. }\end{array}$ \\
\hline & Dawar et $a^{22}$ & 2014 & Case Report & $\begin{array}{l}\text { Simultaneous craniotomy and cesarean section in the } \\
\text { pregnant patient provide better outcome for both the } \\
\text { mother and the baby. }\end{array}$ \\
\hline & Tawfik et al ${ }^{23}$ & 2015 & Case Report & $\begin{array}{l}\text { Case of a term pregnant patient who suffered traumatic } \\
\text { brain injury and was managed by cesarean delivery followed } \\
\text { by craniotomy under general anesthesia }\end{array}$ \\
\hline & Inoue et $\mathrm{al}^{24}$ & 2016 & Case Report & $\begin{array}{l}\text { Pregnancy and intrauterine fetal death can be a risk } \\
\text { factor for paroxysmal sympathetic hyperactivity (PSH) } \\
\text { exacerbation, and delivery can be useful to resolve } \\
\text { refractory PSH and save the mother's life. }\end{array}$ \\
\hline & Kho et al. ${ }^{18}$ & 2018 & Literature Review & $\begin{array}{l}\text { Every woman of reproductive age with significant damage } \\
\text { is still pregnant until proven otherwise by a definitive } \\
\text { pregnancy test or an ultrasound test. }\end{array}$ \\
\hline
\end{tabular}

between pregnant patients with TBI and their nonpregnant counterparts. Adjusting for confounding variables, pregnant patients with TBI had a tendency to increased mortality (adjusted odds ratio [AOR] 2.2; 95\% confidence interval [CI], 0.9-5.1; $p=0.07$ ).

Since all pregnant patients with TBI were between 15 and 47 years old, a separate analysis was performed with this specific age group. The only significant difference between the 2 groups was that pregnant women with TBI were younger (24.9 \pm 7.2 years versus $29.0 \pm 10.2$ years, $p=0.004$ ) than their nonpregnant counterparts with TBI. ${ }^{21}$ The results are summarized in - Table $\mathbf{1}$.

\section{Discussion}

\section{Complications}

For Leroy-Malherbe et al., ${ }^{2}$ in their study of 18 patients with neurological deficiency and with a history of accidents during pregnancy, it was shown that the score on the Glasgow results scale showed good recovery in 6\% (1), moderate disability in 34\% (6), severe disability in 34\% (6), and persistent vegetative score in $20 \%$ (4). The neuroimaging was varied, ranging from normal in 17\% (3) to injuries in $77 \%$ (14), of the most varied types: focal ischemic injury with congenital changes, ischemic injuries restricted to a vascular territory, diffuse ischemic injuries, periventricular leukomalacia, diffuse white matter abnormality, diffuse cortical and white matter atrophy, and a deceased patient had hemorrhagic lesions on pathological examination.

Presence of neurological deficits such as hemiparesis, neonatal seizures, cerebral palsy, hemorrhage or hydrocephalus were observed in children of mothers who suffered trauma during pregnancy. ${ }^{3,8,9}$ A woman exposed to trauma, needing hospitalization during pregnancy, is under a 1.4 times higher risk of having a newborn with cerebral palsy when compared with a woman not exposed to trauma. ${ }^{3}$

It was observed that fetal injuries are more frequent after trauma in advanced pregnancy, with fractures of the skull bones and intracranial hemorrhage in the fetus being the most common, leading to death in most cases. ${ }^{6,8}$ A traumatic origin is clear mainly for depressed skull fractures and cerebral hemorrhage. $^{2}$ Cranial fracture in the fetus is caused by the compression of the fetal head against the surrounding structures, such as the pubic symphysis, the pelvis (whole or fractured), the spine or the promontory. ${ }^{8,9}$ Premature labor associated with trauma appears to be frequent, although it is rarely reported in the immediate postinjury period. ${ }^{13,14}$ Diffuse axonal injury, as a result of strong accelerations/decelerations in the fetal brain, can result in the cessation of the growth of the head. ${ }^{9}$

Maternal hypovolemic shock, disseminated intravascular coagulation, and transient abnormalities of placental blood flow (reduced maternal-placental flow, placental embolization and detachment) can also be pointed out as the etiology for newborn brain injuries, $1,3,6,9,17$ although there are no studies in the literature evaluating the effect of a hypercoagulable state and mortality in pregnant patients who suffered TBI; a hypercoagulable state, theoretically, puts patients at increased risk of complications and mortality. ${ }^{21}$

In addition, TBI-induced coagulopathy as an independent risk factor for increased mortality is well-described. ${ }^{22}$ It is possible that the combination of the two can lead to a deep hypercoagulable state and worsen the result. Berry et al., ${ }^{21}$ in their study comparing pregnant and nonpregnant women who suffered TBI, demonstrated that although it is not 


\section{Urgent care protocol and follow-up of pregnant woman with traumatic brain injury}
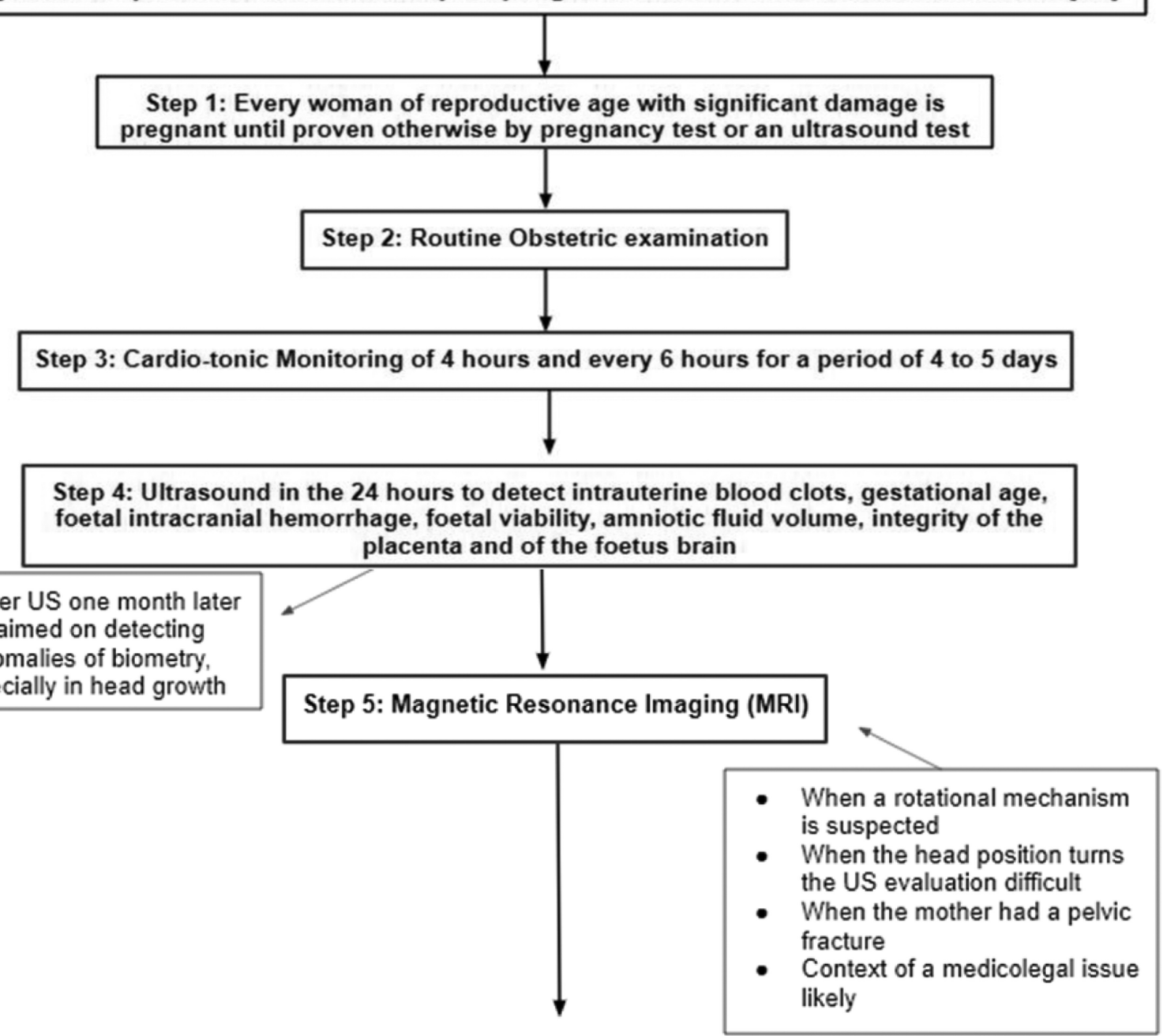

A second MRI have to be done if anomalies or if clear signs of transient foetal distress were register on the first MRI

Fig. 2 Urgent Care Protocol and follow-up of pregnant women with traumatic brain injury. (own authorship).

significant, there was a tendency toward increased mortality in the pregnant TBI group (AOR: 2.0; 95\%CI: 0.8-4.6; $p=0.12$ ), which may be caused by a synergistic effect of a hypercoagulable state induced by pregnancy and coagulopathy induced by TBI.

As the etiologic agents for these types of lesions that should be pointed out as possible differential diagnoses, there are the other environmental factors, as well as perinatal anoxia and genetic factors. ${ }^{9}$ Ultrasound tests are useful to assess the degree of brain damage in the newborn, as well as brain computed tomography (CT) and magnetic resonance imaging (MRI) exams. ${ }^{5,8}$ Suggested protocol for emergency care and monitoring of pregnant women with TBI is shown in - Figure 2.

Another complication is paroxysmal sympathetic hyperactivity (PSH), which is characterized by paroxysms of fever, hypertension, tachycardia, tachypnea, diaphoresis, and dystonic posturing. It was reported by Inoue et al. in a 16-year- old primiparous girl in the $11^{\text {th }}$ week of gestation with who suffered a TBI during a motorcycle accident. From day 2, she developed intermittent episodes of tachycardia with tachypnea, fever, profuse sweating, and extensor posturing, and was diagnosed with PSH. Her condition only improved after delivery, after intrauterine fetal death was confirmed $\left(16^{\text {th }}\right.$ week of gestation, on day 37 of hospitalization). ${ }^{24}$

\section{Pregnant Women in Vegetative State}

The prolongation of a pregnancy in a woman who has suffered severe brain trauma or who is brain dead is within the reach of current medicine. A fetus can develop normally in a comatose patient, despite the existence of complications of this condition (anemia, hypoxia, and digestive hemorrhage) and the use of medications. ${ }^{5,17}$ The question that is not entirely clear, until now, is how long this pregnancy can be prolonged. Some authors have analyzed the use of intensive therapy to prolong a pregnancy for women with a 
gestational age of at least 24 weeks, since there is evidence that somatic death accours 2 to 4 weeks after brain death. ${ }^{17}$

However, case reports have challenged this limit, demonstrating the possibility of prolonging pregnancies with a lower gestational age. ${ }^{5,16,17}$ According to Slattery et al, ${ }^{25}$ a fetus born before 24 weeks of gestation has a limited chance of survival, with the possibility of spontaneous abortion or intrauterine death, especially if the pregnant woman is between 13 and 19 weeks of gestation. ${ }^{20}$ At 24,28 and 32 weeks, a fetus has $\sim 30,80$ and 98 chances of survival, respectively, with 40,10 and $<2 \%$ chance of suffering from a severe disability, respectively. ${ }^{20,25}$

Many factors can cause sequelae to the fetus when the mother is comatose. ${ }^{16}$ During extended life support, patients develop severe complications, including infection, hemodynamic instability, diabetes insipidus, panhypopituitarism, metabolic instability, acute respiratory stress syndrome, and disseminated intravascular coagulation. ${ }^{17,20}$ Maternal malnutrition due to the high catabolism and negative nitrogen balance that occur in individuals immobilized for a long period can affect the weight and brain development of the fetus, $5,16,26$ although some authors refer that the fetus is only affected when the conditions of calorie consumption or protein intake are extreme. ${ }^{16}$

According to the findings of the systematic literature review by Esmaeilzadeh et al, ${ }^{20}$ prolonged somatic care can lead to the delivery of a viable child with a satisfactory Apgar score and birthweight. In addition, children can develop normally without problems resulting from their intrauterine conditions, as there were six children who underwent postneonatal follow-up up for 24 months in the study and they all developed normally and, apparently, had no problems related to their exceptional intrauterine circumstances. Ethical issues must be considered when deciding to prolong a pregnancy of a woman who is brain dead, requiring the active participation of family members. ${ }^{5,17}$ It is also important to address the context of the cost of prolonged use of intensive care resources.

\section{Monitoring and Management}

Increased plasma volume and cardiac output are some of the numerous anatomical and physiological changes that occur during pregnancy, which, combined with the blood diversion provided by the uterus-placental circulation, can mask the signs of hypovolemia. ${ }^{17}$ Compression of the aorta and of the vena cava through the pregnant uterus when the patient is in the supine position can also confuse the interpretation of vital signs. Pregnant patients in a permanent vegetative state require special maternal-fetal monitoring. Uterine activity and fetal heartbeat must be recorded every 8 hours for 30 minutes, ${ }^{17}$ through cardiothoracic graph with manual detection of fetal movements in the mother's abdomen, serial ultrasound for the evaluation of fetal growth, and 24-hour urinary estriol dosage correlated with creatinine clearance are important for the assessment of fetal vitality. ${ }^{16}$ Strict hemodynamic control, blood gas analysis, electrolyte balance, acid-base and nutrition must be performed throughout pregnancy. ${ }^{5}$
In maternal brain death, special attention should be paid to mechanical ventilation. To facilitate the elimination of carbon dioxide from the fetus as a result of the effect of progesterone on the respiratory center, the pregnant woman develops hypocarbia mediated by an increase in tidal volume and respiratory rate. Hypocarbia is compensated by an increase in the excretion of bicarbonate by the kidneys. ${ }^{27}$ The carbon dioxide tension, the tidal volume, and the maternal respiratory rate must be maintained $\sim$ between 29 and $31 \mathrm{~mm} \mathrm{Hg}$, between 6 and $8 \mathrm{ml} / \mathrm{Kg}$, and between 10 and $12 / \mathrm{min}$, respectively, in the normal pregnant woman. ${ }^{281}$

The use of medication may raise some doubts about its effect on the fetus. Few agents have a teratogenic action if administered in the first 12 weeks of pregnancy. The drugs that should be avoided are ergotamines and warfarin derivatives; antibiotics such as aminoglycosides and those containing sulfa should be used with caution due to their adverse effects. $^{5}$

The nutritional support needed by a pregnant woman before and after brain death is not the same. A pregnant woman with brain death will spend $\sim 75 \%$ of the baseline energy expenditure of a healthy pregnant woman. ${ }^{29}$ The feeding route can be initially enteral, through a tube. The gastric emptying of the pregnant patient is slower and, if there is a large gastric residue, variations in the angle of the bed can be made.

The risk of developing deep venous thrombosis is higher during pregnancy because of the immobility and the flaccid paralysis that follows brain death. It is important to do prophylactic anticoagulation, which is effective for the mother and safe for the fetus, with low molecular weight heparin being the safest and most effective medication. ${ }^{20,29,30}$ Prophylaxis of venous thrombosis can be performed using subcutaneous heparin (5000 U, twice a day). ${ }^{17}$ Persistent anemia conditions occasionally require blood transfusion, so the maternal hemoglobin level should be monitored. 8,30

The braindead patient is liable to contract pneumonia due to ventilatory support, kidney and bladder infections due to urinary catheters, and septicemia due to intravascular catheters. ${ }^{20,31}$ Maternal infections should be treated aggressively with the most effective substances, rather than choosing to use substances safe for the fetus, which may not effectively treat the infection. ${ }^{32-35}$

If the patient develops pituitary insufficiency, replacement of thyroid hormone, corticosteroids and synthetic vasopressin should be performed. For fetal lung maturation, corticosteroids should be administered to the mother from the $26^{\text {th }}$ week of gestation with cycles every 10 days. ${ }^{17}$ To avoid prolonged exposure of the fetus to glucocorticoids during maternal support, which are necessary to treat the adrenal insufficiency that usually occurs in brain death and for pulmonarymaturation, prednisone or methylprednisolone should be used, given that they cannot cross the placental barrier. ${ }^{20,25}$ Suggested protocol for monitoring and management of pregnant women in vegetative state is shown in - Figure 3. 


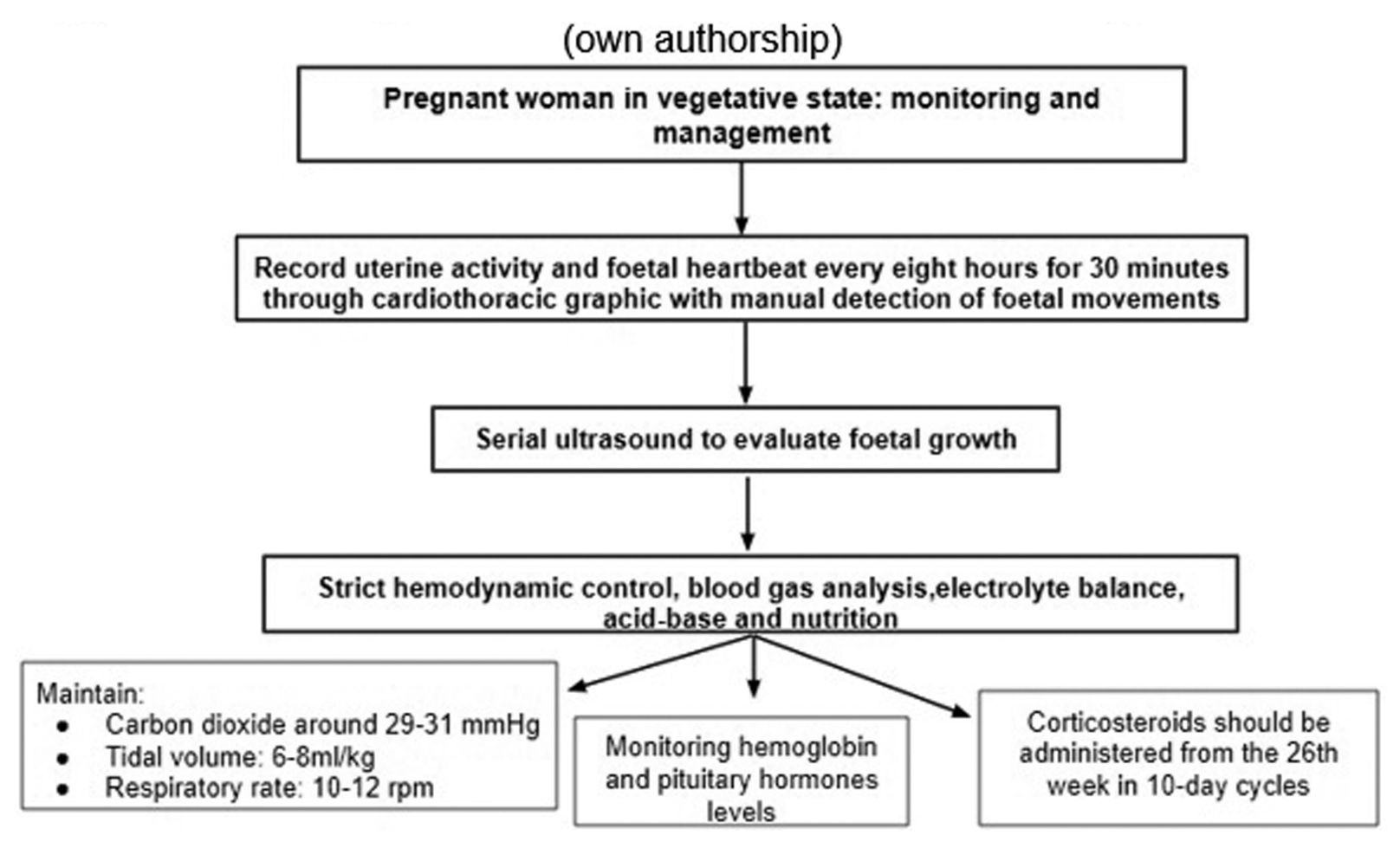

Fig. 3 Monitoring and management of pregnant woman in vegetative state. (own authorship).

\section{Parturition}

Much is questioned about the best route for delivery of mothers in a vegetative state. Even in the best of circumstances, a child with a gestational age $<24$ weeks is unlikely to survive. Therefore, the risks and benefits of an induced delivery or cesarean section should be weighed, which should be reserved for the numerous complications resulting from the maternal state (fetal distress, placental detachment, uterine rupture, and anomalous presentations). ${ }^{5}$ Cesarean sections are indicated in cases of recent maternal death or brain death, knowing that delivery should start within 4 to 5 minutes. ${ }^{5}$ According to the study by Esmaeilzadeh et al, ${ }^{20}$ all deliveries performed on pregnant women with brain death were cesarean, resulting in fetuses born alive.

\section{Study Limitations}

The present study has several limitations, since this is a topic that is rarely discussed in the literature. Due to the scarcity of more robust works on the subject, our casuistic had few works, most of which were case reports, which in fact impoverishes the quality of the meta-analysis.

\section{Conclusion}

For the evaluation of pregnant women with TBI, a protocol is suggested that can be followed in the emergency care service to predict or even minimize the possible future damage that the fetus may suffer. There is no clear limit to restrict support to a pregnant patient in a vegetative state. Therefore, a multidisciplinary approach to the case and strict monitoring of the patient and of the fetus are necessary. More clinical trials and cohort studies on the subject are needed for more accurate data and conclusions.

\section{Conflict of Interests}

The authors have no conflict of interests to declare.

\section{References}

1 Shah KH, Simons RK, Holbrook T, Fortlage D, Winchell RJ, Hoyt DB. Trauma in pregnancy: maternal and fetal outcomes. J Trauma 1998;45(01):83-86

2 Leroy-Malherbe V, Bonnier C, Papiernik E, Groos E, Landrieu P. The association between developmental handicaps and traumatic brain injury during pregnancy: an issue that deserves more systematic evaluation. Brain Inj 2006;20(13-14):1355-1365

3 Gilles MT, Blair E, Watson L, et al. Trauma in pregnancy and cerebral palsy: is there a link? Med J Aust 1996;164(08):500-501

4 Patterson RM. Trauma in pregnancy. Clin Obstet Gynecol 1984;27 (01):32-38

5 Sim KB. Maternal persistent vegetative state with successful fetal outcome. J Korean Med Sci 2001;16(05):669-672

6 Ali J, Yeo A, Gana TJ, McLellan BA. Predictors of fetal mortality in pregnant trauma patients. J Trauma 1997;42(05):782-785

7 Peckham CH, King RW. A study of intercurrent conditions observed during pregnancy. Am J Obstet Gynecol 1963;87(05): 609-624

8 Baethmann M, Kahn T, Lenard HG, Voit T. Fetal CNS damage after exposure to maternal trauma during pregnancy. Acta Paediatr 1996;85(11):1331-1338

9 Yamamoto T, Koeda T, Ishii S, Takeshita K. A patient with cerebral palsy whose mother had a traffic accident during pregnancy: a diffuse axonal injury? Brain Dev 1999;21(05):334-336

10 El-Kady D, Gilbert WM, Anderson J, Danielsen B, Towner D, Smith LH. Trauma during pregnancy: an analysis of maternal and fetal outcomes in a large population. Am J Obstet Gynecol 2004;190 (06):1661-1668 
11 Murphy NJ, Quinlan JD. Trauma in pregnancy: assessment, management, and prevention. Am Fam Physician 2014;90(10):717-722

12 Farmer DL, Adzick NS, Crombleholme WR, Crombleholme TM Longaker MT, Harrison MR. Fetal trauma: relation to maternal injury. J Pediatr Surg 1990;25(07):711-714

13 Goodwin TM, Breen MT. Pregnancy outcome and fetomaternal hemorrhage after noncatastrophic trauma. Am J Obstet Gynecol 1990;162(03):665-671

14 Pearlman MD, Tintinalli JE. Evaluation and treatment of the gravida and fetus following trauma during pregnancy. Obstet Gynecol Clin North Am 1991;18(02):371-381

15 Connolly AM, Katz VL, Bash KL, McMahon MJ, Hansen WF. Trauma and pregnancy. Am J Perinatol 1997;14(06):331-336

16 Ben Aderet, $\mathrm{N}$, et al. Traumatic coma during pregnancy with persistent vegetative state. Case report. British Journal of Obstetrics and Gynaecology 1984;91(01):939-941. Doi: 10.1111/ j.1471-0528.1984.tb03713.x

17 Bernstein IM, Watson M, Simmons GM, Catalano PM, Davis G, Collins R. Maternal brain death and prolonged fetal survival. Obstet Gynecol 1989;74(3 Pt 2):434-437

18 Kho GS, Abdullah JM. Management of severe traumatic brain injury in pregnancy: A body with two lives. Malays J Med Sci 2018;25(05):151-157

19 Suddaby EC, Schaeffer MJ, Brigham LE, Shaver TR. Analysis of organ donors in the peripartum period. J Transpl Coord 1998;8 (01):35-39

20 Esmaeilzadeh M, et al. One life ends, another begins: Management of a brain-dead pregnant mother-A systematic review-. BMC Medicine 2010;8:74. Doi: 10.1186/1741-7015-8-74

21 Berry C, Ley EJ, Mirocha J, Margulies DR, Tillou A, Salim A. Do pregnant women have improved outcomes after traumatic brain injury? Am J Surg 2011;201(04):429-432

22 Dawar P, et al. Decompressive craniectomy in term pregnancy with combined caesarean section for traumatic brain injury. Neurology India 2013;61(04):423-425. Doi: 10.4103/0028-3886.117588
23 Tawfik MM, Badran BA, Eisa AA, Barakat RI. Simultaneous cesarean delivery and craniotomy in a term pregnant patient with traumatic brain injury. Saudi J Anaesth 2015;9(02):207-210

24 Inoue A, Ebina M, Atsumi T, Ariyoshi K. Refractory paroxysmal sympathetic hyperactivity following brain injury in a pregnant woman that dramatically improved after delivery. Acute Med Surg 2015;3(03):268-271

25 Slattery MM, Morrison JJ. Preterm delivery. Lancet 2002;360 (9344):1489-1497

26 Luke B. Nutritional influences on fetal growth. Clin Obstet Gynecol 1994;37(03):538-549

27 Bhatia P, Bhatia K. Pregnancy and the lungs. Postgrad Med J 2000; 76(901):683-689

28 Milliez J, Cayol V. Palliative care with pregnant women. Best Pract Res Clin Obstet Gynaecol 2001;15(02):323-331

29 Dominguez-Roldan JM, Murillo-Cabezas F, Santamaria-Mifsut JL, Muñoz-Sanchez A, Villen-Nieto J, Barrera-Chacon JM. Changes in resting energy expenditure after development of brain death. Transplant Proc 1995;27(04):2397-2398

30 Villa-Forte Gomes MP. Venous thromboembolism in pregnancy. Curr Treat Options Cardiovasc Med 2009;11(02):104-113

31 Farragher RA, Laffey JG. Maternal brain death and somatic support. Neurocrit Care 2005;3(02):99-106

32 Korzeniowski OM. Antibacterial agents in pregnancy. Infect Dis Clin North Am 1995;9(03):639-651

33 Einarson A, Shuhaiber S, Koren G. Effects of antibacterials on the unborn child: what is known and how should this influence prescribing. Paediatr Drugs 2001;3(11):803-816

34 Christensen B. Which antibiotics are appropriate for treating bacteriuria in pregnancy? The Journal of Antimicrobial Chemotherapy 2000;46(suppl 1):29-34. Discussion 63-65.

35 van Runnard Heimel PJ, Franx A, Schobben AFAM, Huisjes AJM, Derks JB, Bruinse HW. Corticosteroids, pregnancy, and HELLP syndrome: a review. Obstet Gynecol Surv 2005;60(01):57-70, quiz $73-74$ 